\title{
Preparation and Performance Evaluation of a Composite Crosslinking Agent
}

\author{
Sun Lei, Zhang Guiqing, Xu Hongzhi", Hao Zhiwei, Xia Ye \\ Engineering Technology Research Company Limited, China National Petroleum Corporation, Tianjin, China \\ Email address: \\ sunlei3@cnpc.com.cn (Xu Hongzhi) \\ ${ }^{*}$ Corresponding author
}

To cite this article:

Sun Lei, Zhang Guiqing, Xu Hongzhi, Hao Zhiwei, Xia Ye. Preparation and Performance Evaluation of a Composite crosslinking Agent. American Journal of Applied Chemistry. Vol. 6, No. 3, 2018, pp. 71-77. doi: 10.11648/j.ajac.20180603.11

Received: April 18, 2018; Accepted: May 3, 2018; Published: May 22, 2018

\begin{abstract}
A water-soluble phenolic resin composite crosslinking agent was synthesized by the combination of water-soluble phenolic resin and metal ions promote cross-linking agent. The water-soluble excellent multi-methylol phenolic resin was synthesized by two-step method, followed by addition of an appropriate amount of metal ions to improve their gelling properties. The two-step method could promote the reaction of phenol and formaldehyde, so the main product was multimethylol phenolic resin. The introduction of metal ions promoted cross-linking agent to make excellent gelling properties. This new kind of crosslinking agent was odor less, low toxicity, and efficient. Based on this kind of water-soluble phenolic resin composite crosslinking agent, the partially hydrolysed polyacrylamide showed good gelling properties. The minimum amount of cross-linking agent was $0.1 \%$ with high gelling strength; its gelation temperature could be adjusted from $60^{\circ} \mathrm{C}-120^{\circ} \mathrm{C}$ and its gelling time could be controlled between $8 \mathrm{~h}$ and $48 \mathrm{~h}$. The stability of gel system was more than 60 days. The composite crosslinking agent has great prospects in the field of oilfield water shutoff profile.
\end{abstract}

Keywords: Crosslinking Agents, Phenolic Resin, Polyacrylamide, Gel Time, Metal Ions

\section{Introduction}

Polymer gel technology can effectively expand the sweep volume and increase the oil displacement efficiency [1-2]. It is mainly used in the oil layer with the large pore channel, the crack and the permeability of the layer [3]. Partially hydrolyzed polyacrylamide (HPAM) and its modified products are widely used in the field of gel flooding. HPAM uses the amide and carboxyl groups it takes to adsorb on the surface of the rock rich in hydroxyl, while the rest is left in space to block out the aquifer. The surface of the rock in the oil layer is covered by oil and cannot provide enough hydroxyl, so HPAM will not absorb on the oil layer, which will not cause blockage of the oil layer [4-6].

The commonly used crosslinking agents of HPAM are inorganic salts and organic phenolic compounds [7]. Mainly inorganic crosslinking agent are chromium acetic acid, citric acid, aluminum high valence metal complex, according to complexation, such high metal ions with HPAM chain carboxylic acid root couplet net structure, with the overall liquidity and has certain strength of the gel [8-12]. Due to the large amount of the crosslinking agent, it is easy to cause pollution to the environment, and it is also susceptible to the influence of salinity. Therefore, it is restricted in use [13-14]. The main components of organic phenolic compounds are phenol and formaldehyde, which can be combined with carboxyl group by covalent bonding to network structure. It is common used because of its controllable crosslinking speed, better stability of gel. But due to the extensive use of phenol and formaldehyde, this sort of crosslinking agent often excitant strong toxicity is larger, at the same time need high gel temperature, gel time is longer, to a certain extent, restrict the scope of its application.

A compound crosslinking agent based on water-soluble phenolic resin is prepared in this paper. First through molecular design, the two-step method are used to get hydroxymethyl water-soluble phenolic resin, then introduce a certain amount of homemade metal ions as promoting 
crosslinking agent, then the water soluble phenolic resin based composite crosslinking agent are prepared. The composite crosslinking agent compared with the conventional phenolic resin crosslinking agent, it has long shelf life, without excitant odour, low toxicity, gelling time shorter, gel strength, gel stability is better, a wider range of applicable temperature and the concentration and can be widely used in oil field water shutoff profile control field.

\section{Experimental Section}

\subsection{Materials and Equipment}

Formaldehyde solution, 37\%; Phenol, analysis pure; Sodium hydroxide, analysis pure; metal ion-promoting crosslinker, self-made; Partially hydrolyzed polyacrylamide, HPAM, molecular weight 25million, hydrolysis $25 \%$, industrial products.

Electronic balance; Electric thermostatic drying oven; RS6000 rotational flow Instrument.

\subsection{Preparation of Composite Crosslinking Agent}

\subsubsection{Water Soluble Phenolic Resin synthesis}

Put the three flask with the mixer and condenser in the electric thermostatic water bath, add phenol $30.0 \mathrm{~g}$, and heat up to $60^{\circ} \mathrm{C}$. When the phenol is fully melted, add to sodium hydroxide $1.5 \mathrm{~g}$ and maintain at $60^{\circ} \mathrm{C}$ for $20 \mathrm{~min}$. Then add $37 \%$ of formaldehyde solution $55.0 \mathrm{~g}$, heat up to $65^{\circ} \mathrm{C}$, and stirring for $50 \mathrm{~min}$. Add sodium hydroxide $1.0 \mathrm{~g}$, elevated flask temperature to $70^{\circ} \mathrm{C}$, thermostatic mixing $20 \mathrm{~min}$. Rejoin $37 \%$ of formaldehyde solution $12.5 \mathrm{~g}$, the constant temperature agitation reaction for $30 \mathrm{~min}$, finally gets the liquid which is bright brown red and can be completely dissolved in water, namely water soluble phenolic resin.

\subsubsection{Preparation of Composite Crosslinking Agent}

The prepared water soluble phenolic resin solution $10.0 \mathrm{~g}$ is taken respectively, and a certain amount of metal ions is added to the crosslinking agent, which is mixed evenly with different compound crosslinking agent.

\subsection{Preparation of HPAM Solution}

The configuration of the different concentration of HPAM solution: accurate weighing $1.0 \mathrm{~g}, 1.5 \mathrm{~g}, 2.0 \mathrm{~g}, 2.5 \mathrm{~g}, 3.0 \mathrm{~g}$, $4.0 \mathrm{~g}$ of HPAM solids, under the condition of rapid mixing, slowly add to $1000 \mathrm{~mL}$ water, keep stirring $2 \mathrm{~h}$, let stand at room temperature overnight after dissolved.

\subsection{Preparation of HPAM/Composite Crosslinking Agent System}

\subsubsection{The effect of Phenolic Resin Concentration on Gel Strength}

The water soluble phenolic resin $0.1 \mathrm{~g}, 0.2 \mathrm{~g}, 0.3 \mathrm{~g}, 0.4 \mathrm{~g}$, $0.5 \mathrm{~g}, 0.6 \mathrm{~g}, 0.7 \mathrm{~g}$ and $1.0 \mathrm{~g}$ were respectively obtained, and then $0.01 \mathrm{~g}$ of metal ions were added to prepare the composite crosslinking agent. Add the above composite crosslinking agent to $100.0 \mathrm{~g} 0.3 \mathrm{wt} \%$ of HPAM solution, mixing evenly, static come glue under $80^{\circ} \mathrm{C}$ constant temperature box. The temperature is set as the gelatinization temperature when the viscosity is determined, and the shear rate is $1.5 \mathrm{~s}^{-1}$ using the PZ38 rotor.

\subsubsection{Effect of Metalion-Promoting Cross-Linker Agent on Gel Strength}

The composite crosslinking agent of water soluble phenolic resin is prepared by adding the metal ion-promoting crosslinker agent $0.0025 \mathrm{~g}, 0.005 \mathrm{~g}, 0.0075 \mathrm{~g}, 0.01 \mathrm{~g}, 0.0125 \mathrm{~g}, 0.015 \mathrm{~g}$, $0.02 \mathrm{~g}$ and $0.025 \mathrm{~g}$ to Water soluble phenolic resin $0.2 \mathrm{~g}$.

Add the above composite crosslinking agent to $100 \mathrm{~g}$ $0.3 \mathrm{wt} \%$ of HPAM solution, mixing evenly, static come glue under $80^{\circ} \mathrm{C}$ constant temperature box.

\subsubsection{The Effect of HPAM Concentration on Gel Strength}

The water soluble phenolic resin $0.2 \mathrm{~g}$ and metal ionpromoting cross-linker agent $0.01 \mathrm{~g}$ are mixed to get watersoluble phenolic resin composite crosslinking agent. The composite crosslinking agents were added to $100.0 \mathrm{~g} 0.1$ wt $\%, 0.15$ wt $\%, 0.2$ wt $\%, 0.25$ wt $\%, 0.3$ wt $\%$ and 0.4 wt $\%$ of HPAM solution respectively, then well mixed

\subsubsection{Effect of Temperature on Gel Strength}

The composite crosslinking agent is added to $100.0 \mathrm{~g}$ of HPAM solution with a mass fraction of $0.3 \%$, and the mixture is evenly mixed, and the mixture is placed in $60^{\circ} \mathrm{C}$, $70^{\circ} \mathrm{C}, 80^{\circ} \mathrm{C}, 95^{\circ} \mathrm{C}$ and $120^{\circ} \mathrm{C}$ cases.

\subsubsection{Effect of pH of Solution on Gel Strength}

Prepare $100.0 \mathrm{~g} 0.3 \mathrm{wt} \%$ of HPAM solution with different $\mathrm{pH}$ of $4,5,6,7,8,9,10$, adding the composite crosslinking agent, mixing well, placed in a thermostat at $80^{\circ} \mathrm{C}$.

\subsubsection{Effect of Salinity on Adhesive Strength}

Make up 100.0g 0.3wt\% HPAM solution with different $\mathrm{NaCl}$ contention of $2000 \mathrm{mg} / \mathrm{L}, 5000 \mathrm{mg} / \mathrm{L}, 10000 \mathrm{mg} / \mathrm{L}$, $15000 \mathrm{mg} / \mathrm{L}, 20000 \mathrm{mg} / \mathrm{L}$, water-soluble phenolic resin composite crosslinking agent is added in to the solution, placed in a thermostat at $80^{\circ} \mathrm{C}$.

Make up 100.0g 0.3wt\% HPAM solution with different $\mathrm{CaCl}_{2}$ contention of $500 \mathrm{mg} / \mathrm{L}, 1000 \mathrm{mg} / \mathrm{L}, 1500 \mathrm{mg} / \mathrm{L}, 3000$ $\mathrm{mg} / \mathrm{L}, 5000 \mathrm{mg} / \mathrm{L}$, composite crosslinking agent is added in to the solution, placed in a thermostat at $80^{\circ} \mathrm{C}$.

\subsubsection{Gel Stability Evaluation}

$0.2 \mathrm{~g}$ composite crosslinking agent is added into $100.0 \mathrm{~g}$ $0.3 \mathrm{wt} \%$ HPAM solution, mixing evenly, placed in a thermostat at $80^{\circ} \mathrm{C}$, take out the gel strength every once in a while.

\section{Results and Discussions}

\subsection{Synthesis of Composite Crosslinking Agent}

In this paper, the hydroxymethylation reaction of phenol is prepared by two-step catalysis. The obtained water-soluble phenolic resin is brownish red liquid, which can be mixed with water at any rate, and the density is $1.18 \pm 0.01 \mathrm{~g} / \mathrm{cm}^{3}$, the solid content is about $50.98 \pm 1.0 \%$, its $\mathrm{pH}$ of aqueous solution 
$(1.0 \mathrm{wt} \%)$ is $8-9$.

\subsection{The Effect of Water Soluble Phenolic Concentration on Gel Strength}

In order to determine the optimal dosage of the crosslinking agent for the HPAM system, the relationship between the water soluble phenolic dosage and the gel strength is studied. The quality fraction of HPAM is $0.3 \%$, and the amount of metal ion-promoting cross-linker agent is $0.01 \%$. At $80^{\circ} \mathrm{C}$, the relationship between water soluble phenolic dosage and gelatinization strength is shown in Figure 1.

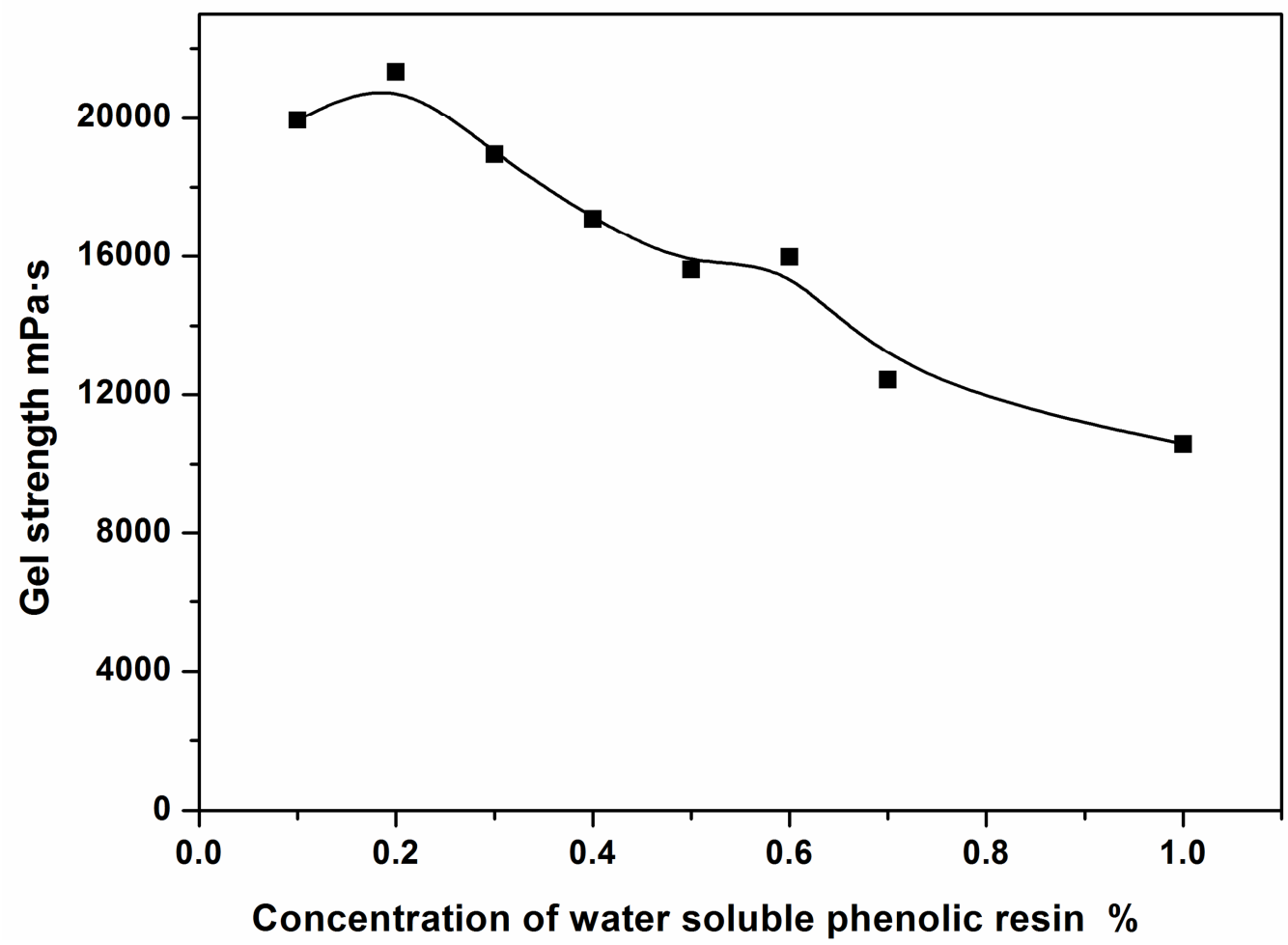

Figure 1. The relationship between water soluble phenolic dosage and gelatinization strength.

When the dosage of crosslinking agent is $0.1 \%$ and $0.2 \%$, the system viscosity are more than $20000 \mathrm{mPa}$, with the further increase in the amount of crosslinking agent, the system viscosity showed a trend of gradual decline. When the dosage of crosslinking agent is $1.0 \%$, the system viscosity fell to $11800 \mathrm{mPa}$ s. This is due to the overdose of crosslinking agent, which leads to a large number of crosslinking points, small molecular weight, large elastic modulus and poor resilience. Accordingly, the optimal dosage of water soluble phenolic in this system should be $0.1 \% \sim 0.2 \%$.

\subsection{The Influence of Metalion-Promoting Cross-Linker Agent on the Gel Strength}

When using water soluble phenolic resin as the crosslinking agent, the gel time is longer, which usually takes 5-7 days, and the gel strength is low, around 5000$8000 \mathrm{mPa}$ s. After adding a small amount of metal ionpromoting cross-linker agent, it can be greatly improved into the gel speed, which can be gelatinized in one day. At the same time, the gel strength also increased significantly, about $20000 \mathrm{mPa}$.

This is due to the rapid complexation of metal ions and carboxylic acid groups in the form of coordination bonds; and phenolic resin crosslinking agent and polyacrylamide amide crosslinking are combined in the form of covalent cross-linking, complexing crosslinking and chemical crosslinking cooperate with each other, which lead to speed up the crosslinking effect.

Figure 2 shows the relationship between the amount of metal ion-promoting cross-linker agent and the gel strength, and a small amount of metal ion promoting crosslinking agent can have a significant effect on the gelation time and the adhesive strength. Adding $0.005 \%$ metal ions promoting crosslinking agent can make the gel strength more than $20000 \mathrm{mPa}$ s. When increasing the dosage to $0.01 \%$, the gel strength is $23520 \mathrm{mPa} \mathrm{s}$, with further increasing, the gel strength is slightly reduced. 


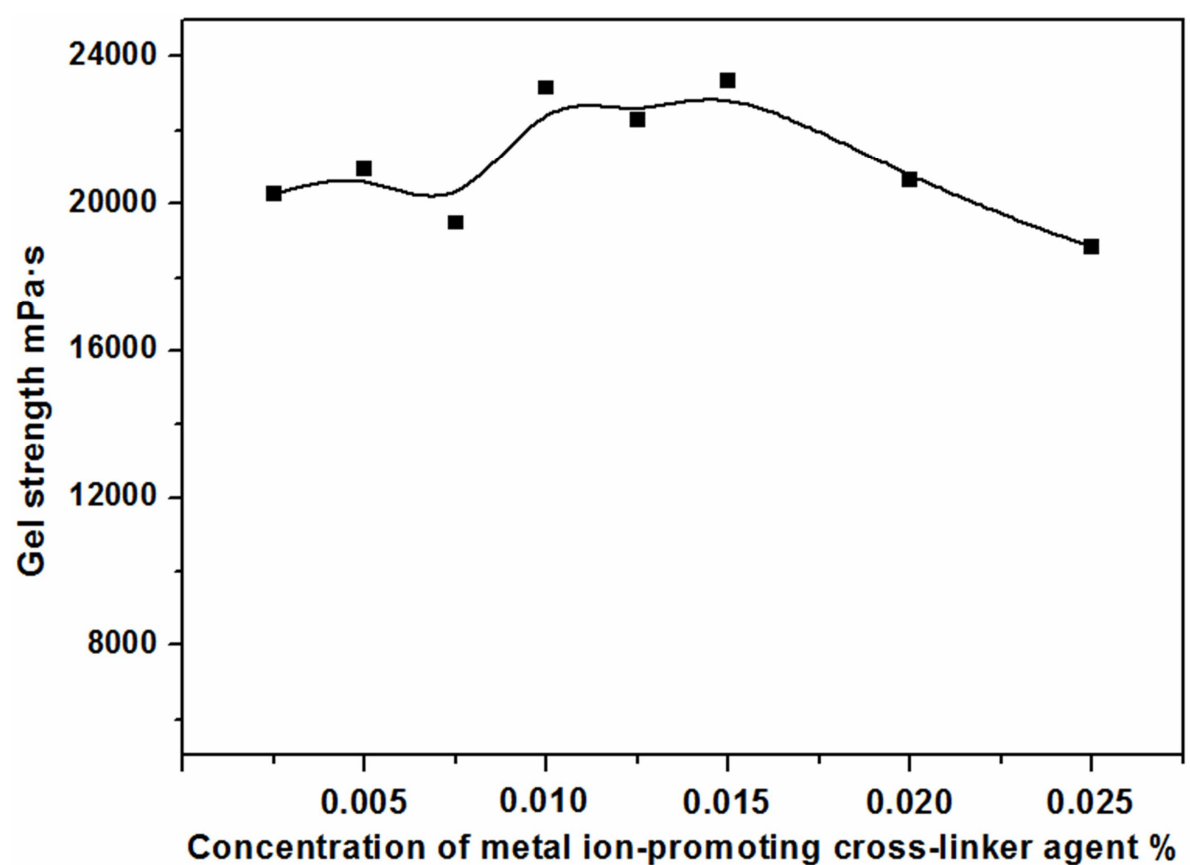

Figure 2. The relationship between the concentration of metal ion-promoting cross-linker agent and the gel strength.

\subsection{The Effect of HPAM Concentration on Gel Strength}

The concentration of HPAM has a significant influence on the gel strength. Figure 3 shows the gel strength under different HPAM concentrations.

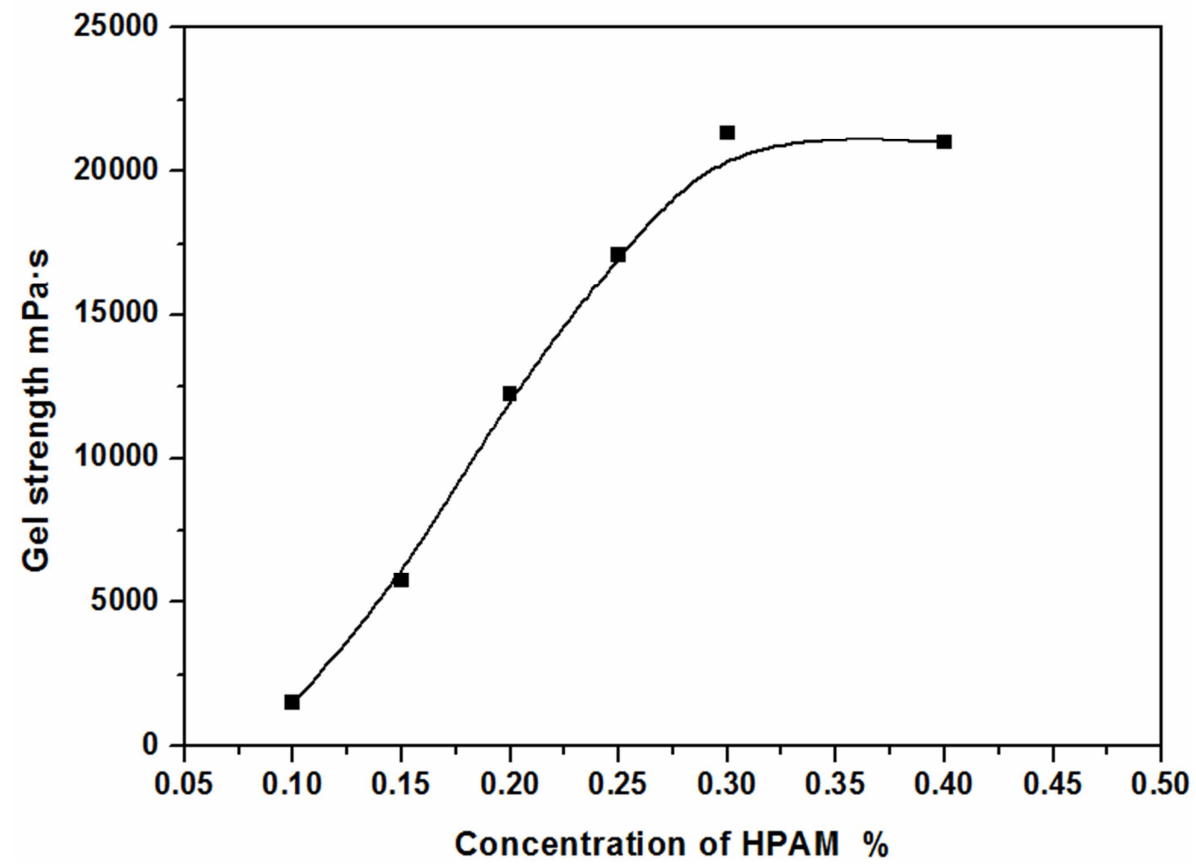

Figure 3 The relationship between the concentration of HPAM and the gel strength.

When the dosage of HPAM is $0.1 \%$, the system did not become gel. As the amount of HPAM increases, the gel strength increased significantly, and while the dosage is $0.2 \%$, the system strength is above $10000 \mathrm{mPa} \cdot \mathrm{s}$. When the dosage of HPAM is $0.3 \%$, the gel strength of the system is above $20000 \mathrm{mPa} \cdot \mathrm{s}$, after that the enhancement of the strength is not obvious as amount of HPAM is increased again.

\subsection{The effect of Temperature on the Gel Strength}

Different temperature has a significant influence on gel time and gel strength, the Figure 4 shows that at $60-80^{\circ} \mathrm{C}$, gel strength is $20000 \mathrm{mPa} \mathrm{s}$; at $95^{\circ} \mathrm{C}$ and $120^{\circ} \mathrm{C}$, the gel strength slightly down to $12000-13000 \mathrm{mPa}$. 


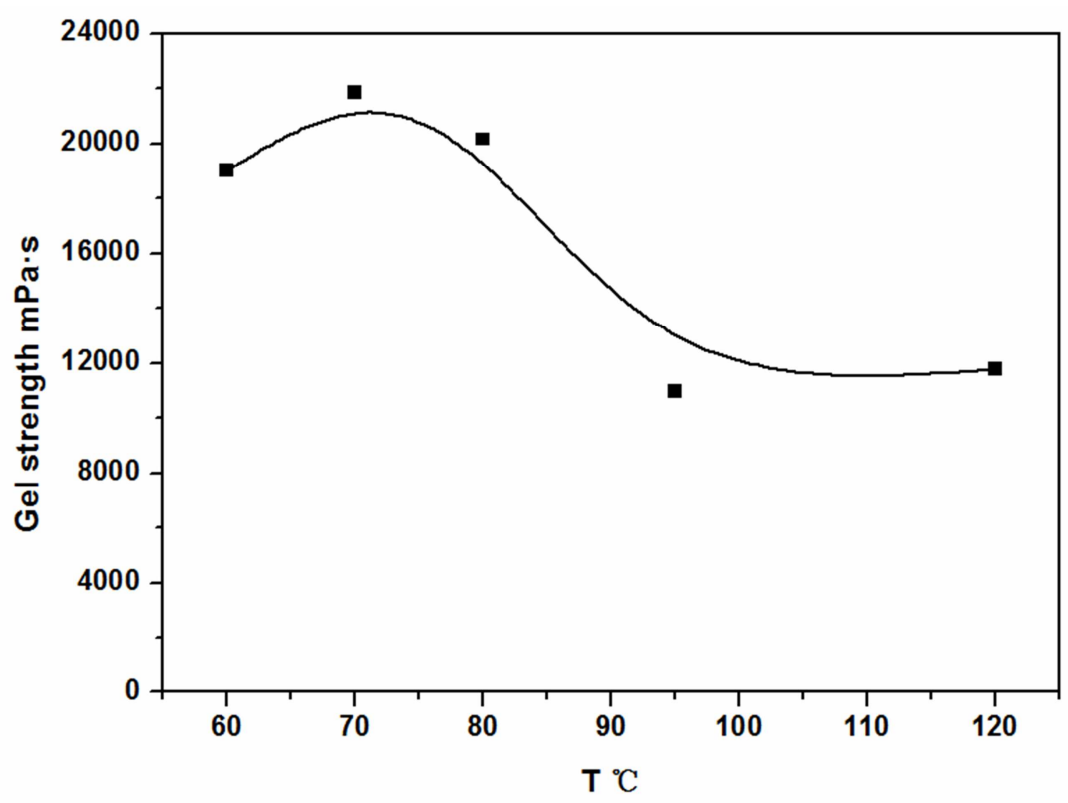

Figure 4. Gel strength under different temperature.

In the case of gelatinization time, the gelatinization time is $1-2$ days at $60^{\circ} \mathrm{C}$, and 1 days at $70^{\circ} \mathrm{C}$, less than 1 day at $80^{\circ} \mathrm{C}$, while at $95^{\circ} \mathrm{C}$ and $120^{\circ} \mathrm{C}$, the gelatinization time is fless than $12 \mathrm{~h}$.

\subsection{The Effect of Solution pH on Gel Strength}

The $\mathrm{pH}$ at various stratum environments is different, and the $\mathrm{pH}$ will also have an effect on the gelation. As shown in Figure.5, when the $\mathrm{pH}$ is 4 , the system has weak gel strength.
This is because the system is too acidic to help the crosslinking reaction. In the range of $\mathrm{pH} 5-9$, the system has good gel performance, and the gel time is about 1 day, and the gel strength is between 20000 and $25000 \mathrm{mPa} \cdot \mathrm{s}$. When the $\mathrm{pH}$ is higher than 10 , the gel strength of the system decreased to $11000 \mathrm{mPa} \cdot \mathrm{s}$ significantly. According to the experimental results, the applicable $\mathrm{pH}$ range of this system is 5-9, which can meet the needs of water shutoff in most areas.

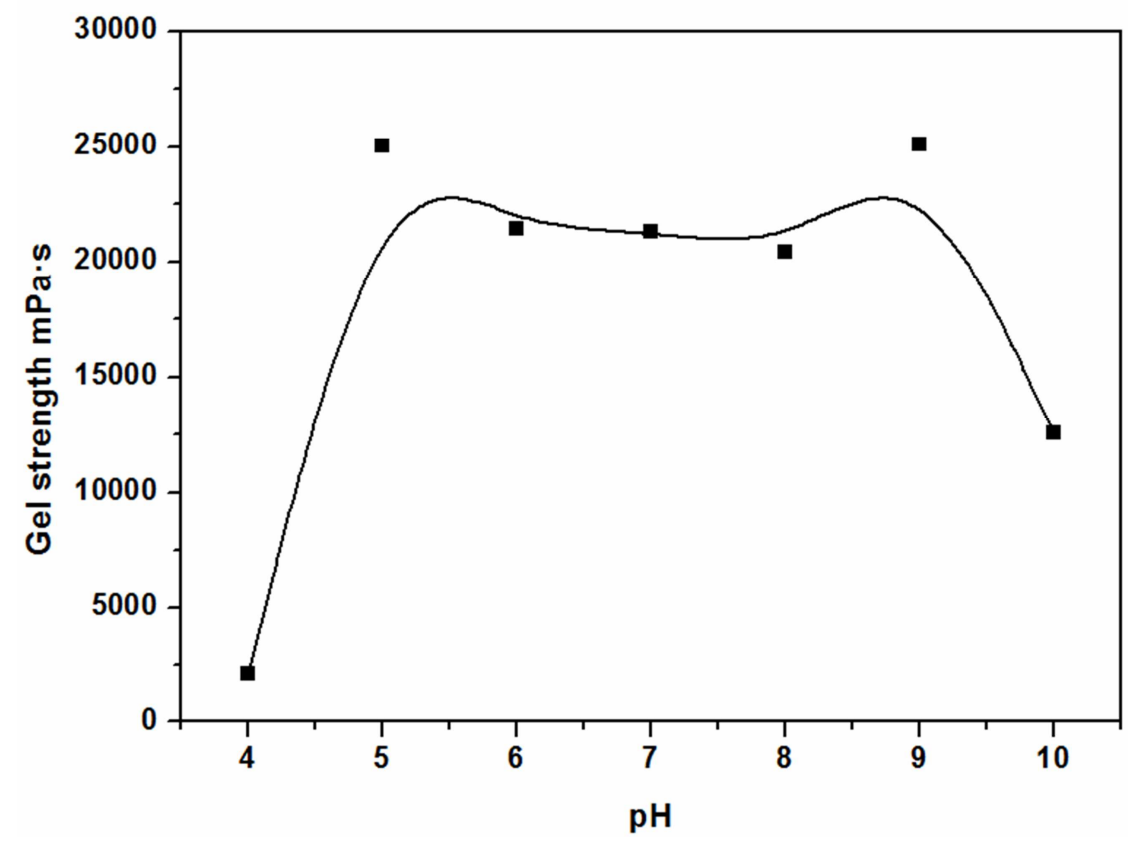

Figure.5. Gel strength under different $p H$.

\subsection{The Effect of Salinity on Gel Strength}

Furthermore, the effect $\mathrm{Na}^{+}$and $\mathrm{Ca}^{2+}$ concentration on gelation performance is investigated. As Figure 6 shows, when the concentration of $\mathrm{Na}^{+}$is less than $5000 \mathrm{mg} / \mathrm{L}$, the gel strength greater than $12000 \mathrm{mPa}$ s, the gel strength drops 
rapidly when $\mathrm{Na}^{+}$concentration is further improved, when the concentration of $\mathrm{Na}^{+}$is $20000 \mathrm{mg} / \mathrm{L}$, gel strength is about $1500 \mathrm{mPa}$ s.

The effect of $\mathrm{Ca}^{2+}$ on gel strength is more obvious. When the $\mathrm{Ca}^{2+}$ concentration is $500-1500 \mathrm{mg} / \mathrm{L}$, the gel strength is about $6000 \mathrm{mPa}$ s. When $\mathrm{Ca}^{2+}$ is raised to $5000 \mathrm{mg} / \mathrm{L}$, the strength of the system is reduced to less than $4000 \mathrm{mPa}$ s.
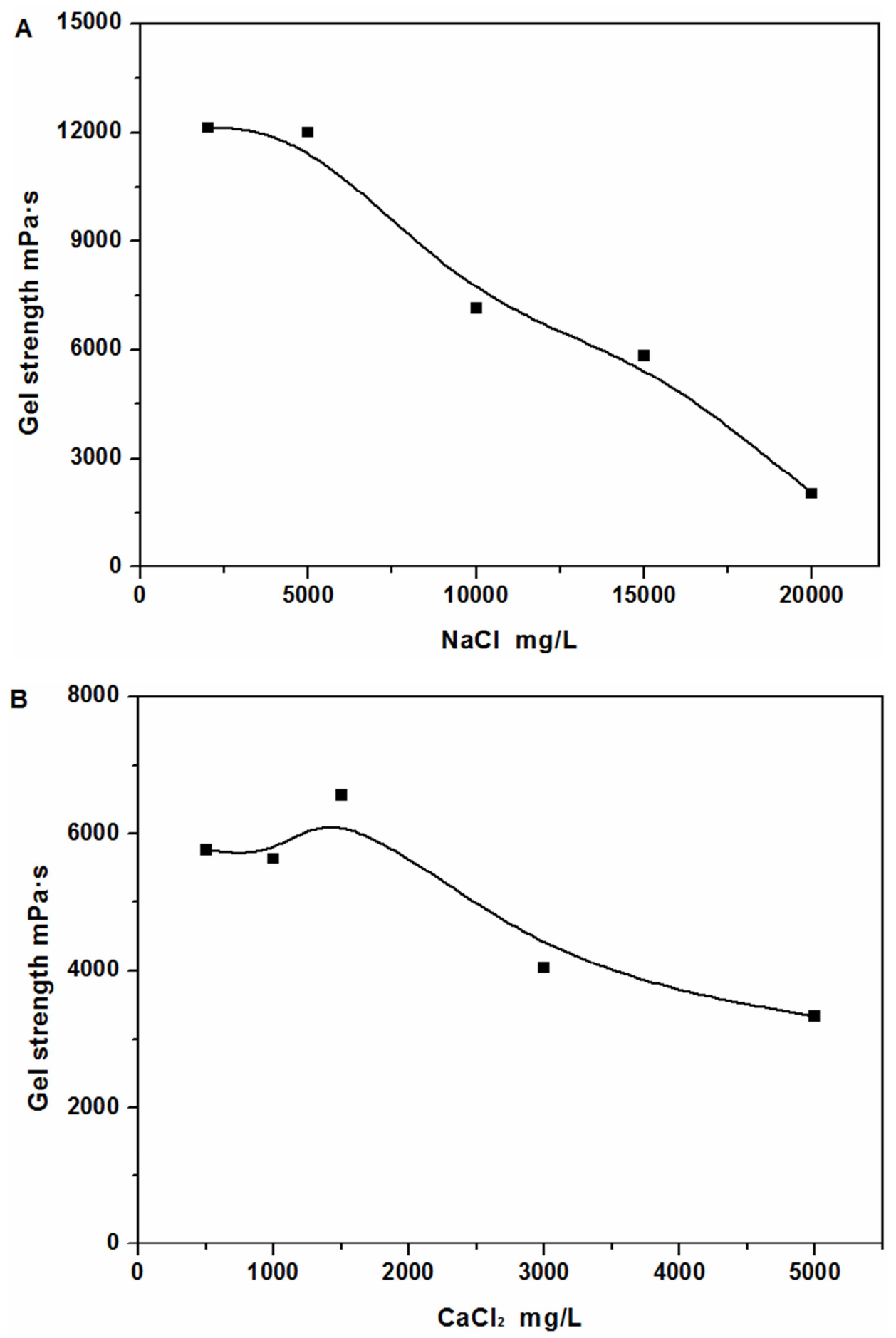

Figure 6. Effect of $\mathrm{NaCl}$ and $\mathrm{CaCl}_{2}$ concentration on gel strength.

\subsection{Stability Evaluation of Gel}

The temperature of $60^{\circ} \mathrm{C}$ and $80^{\circ} \mathrm{C}$ were selected to evaluate the stability of the polymer gel after gelation. The results are shown in Table 1.

Table 1. Gel stability.

\begin{tabular}{lllllll}
\hline \multirow{2}{*}{$\mathbf{T} /{ }^{\circ} \mathbf{C}$} & \multicolumn{6}{l}{ Gel strength $/ \mathbf{m P a} \cdot \mathbf{l}$} \\
\cline { 2 - 7 } & 1day & 3days & 7days & 15days & 30days & 60days \\
\hline 60 & 24061 & 24561 & 25612 & 25864 & 27056 & 25124 \\
80 & 15880 & 15448 & 16458 & 17985 & 19142 & 16543 \\
\hline
\end{tabular}


From Table 1, it can be seen that, at these two temperatures, the gelatinizing stability is excellent, and the initial gelatinization degree is about $24061 \mathrm{mPa} \cdot \mathrm{s}$ at $60^{\circ} \mathrm{C}$, the gel strength is about $25612 \mathrm{mPa} \bullet \mathrm{s}$ after 7 days, and the gel strength increased slowly to $27056 \mathrm{mPa} \bullet$ s after 30 days.

Under $80^{\circ} \mathrm{C}$ conditions, the initial gel strength is about $15886 \mathrm{mPa} \cdot \mathrm{s}$, and the gel strength is approximately $16458 \mathrm{mPa} \cdot \mathrm{s}$ after 7days, and increased slowly to $19142 \mathrm{mPa} \bullet$ s after 30 days.

It is proved that the gel system based on the water soluble phenolic resin composite crosslinking is good, and it can be stable for a long time.

\section{Conclusion}

The polyhydroxymethyl water-soluble phenolic resin is prepared by molecular design, and a composite cross-linking agent is obtained by acting together with a metal ionpromoting cross-linker.

The water-soluble phenolic resin synthesized by the twostep method has a higher degree of reaction between phenol and formaldehyde, and is more in the form of polymethylol phenol, which reduces the content of free phenol and formaldehyde. Meanwhile, the introduction of a metal ionpromoting cross-linker greatly shorten the gelation time and improves the gel strength.

In this paper, the content of free phenol and formaldehyde is reduced, and the introduction of metal ionic crosslinking agent greatly shortened the time of gelatinization and enhanced the adhesive strength.

Through the preferred experiments, it is determined that the optimum amount of the cross-linking agent is $0.2 \%$; the amount of the applicable polymer is $0.3 \%$; the applicable temperature is $60^{\circ} \mathrm{C}-120^{\circ} \mathrm{C}$, with the optimal range of $60^{\circ} \mathrm{C}$ $80^{\circ} \mathrm{C}$; applicable $\mathrm{pH}$ is $6-9$, also can be used with certain sodium and calcium tolerance. Compared with conventional organic phenolic cross-linking agents and inorganic crosslinking agents, the composite cross-linking agent can form a gel more quickly within one day or so; the gelation strength is greater, and can be more than $15000 \mathrm{mPa} \bullet \mathrm{s}$; The gel stability is better, and the gel strength at storage for more than two months at high temperature is almost unchanged. The composite crosslinking agent has great application potential in the field of water shutoff and profile control in oil fields.

\section{References}

[1] ZHAO G, DAI C, CHEN A, et al. Experimental study and application of gels formed by nonionic polyacrylamide and phenolic resin for in-depth profile control [J]. Journal of Petroleum Science and Engineering, 2015, 135: 552-560.
[2] YANG Z G. Development of technology of tertiary oil recovery $[\mathrm{J}]$. Chemical Industry and Engineering Progress, 2011, 30(s1): 420-423.

[3] BAI B J, ZHOU J, YIN M F. A comprehensive review of polyacrylamide polymer gels for conformance control [J]. Petroleum Exploration and Development, 2015, 42(4): 481487.

[4] El-KARSANI K S M, Al-MUNTASHERI G A, HUSSEIN I A. Polymer systems for water shutoff and profile modification: a review over the last decade [J]. SPE Journal, 2014, 19(1): 135-149.

[5] XU D J, ZHENG Y F, ZHAG S, et al. Application progress of weak gel systems in oilfield profile control technology $[\mathrm{J}]$. Chemical Industry and Engineering Progress, 2015, 34(5): 1323-1331.

[6] Zhao X Y, LI X R, Ma G Y. A laboratory performance study on amphoteric hydrophobically associating polyacrylamide [J]. Applied Chemical Industry, 2018(2): 250-253.

[7] SHI J H, WEI X M. Synthesis and evaluation of polymer oil displacement agent crosslinked by phenolaldehyde resin prepolymer [J]. Advances in Fine Petrochemicals, 2003, 4(7): 45-48.

[8] Xi Z H, Dang G C, Wang L Y, et al. Performance research of copolymer fracturing fluid system [J]. Applied Chemical Industry, 2017, 10: 1934-1937.

[9] WANG J Y, Kong Y, Zhao C X, et al. Effect of polymer hydrolysis degree on the gel performance of organic chrome cross linker [J]. Chemical Engineer, 2015, 4: 75-76.

[10] TANG H Y, XIAO Q G, XU H B, et al. Progress of new chromium chemicals: organic chromium complexes [J]. Chemical Industry and Engineering Progress, 2013, 32 (9): 2205-2215.

[11] LI C N, LEI K, ZHU M D. Study on the synthesis and performance evaluation of aluminum citrate crosslinking agent [J]. Chemical Engineer, 2013(5): 14-16.

[12] JING Y, ZHANG S C, LV X. Preparation of particulated precrosslinked acrylamide tercopolymer/bentonite complex as diverting agent LJ-1 [J]. Oilfield Chemistry, 2005, 22(4): 354357.

[13] LUO Y, LIU D N, HU Q P, et al. Microencapsulation of organic chromium crosslinker for polymer gelling fluid as water shutoff/profile modification agent [J]. Oilfield Chemistry, 2009, 26(4): 391-394.

[14] ZHANG Y C, WANG S J. A simple method for preparing water-soluble phenol-formaldehyde resin $[\mathrm{J}]$. China Adhesives, 2004, 13 (2): 9-11. 